peritoneal cavity is entered by an incision one inch long transverse to the body axis and parallel to the nerves. This incision is easily closed since the natural tension of the parts approximates the edges. Should difficulties be encountered in the removal of the appendix and a large incision be required it can be obtained by the usual vertical incision in the posterior rectus sheath.

The incision for perforated ulcer of the stomach.-In many cases of perforating ulcer of the stomach or the duodenum it is a matter of doubt as to whether the pelvis has become infected or not. Even after the usual epigastric incision the same doubt remains, since the state of the middle area of the abdomen is no criterion as to that of the lower portion. The only method of settling the point is by making an incision in the hypogastrium. Should this be made after the upper incision there is danger of infecting the pelvis if this prove clean, since hands and instruments are already soiled. It therefore seems advisable in cases of doubt to make the hypogastric incision first. The state of the pelris can then be ascertained and if found clean the wound can be closed. If the contrary prove to be the case the lower wound can be used in the process of cleansing the peritoneum. The primary lower incision is also of service in determining the condition of the appendix when there is doubt as to whether the appendix region or the upper part of the intestinal tract is at fault.

Upper Wimpole-street, $\mathrm{W}$.

\section{A CASE OF ACUTE IODINE POISONING WITH FATAL RESULT.}

By E. Donaldonon-Sim, M.R.C.S. ENG., L.R.C.P. Lond., SENIOR RESIDENT MEDICAL OFFICER AT THE GUEST HOSPITAL, DUDLEY.

A MAN, aged 52 years, was admitted to the Guest Hospital, Dudley, on the morning of Jan. 25th, 1905, with an outward dislocation of the right foot and a simple fracture of the right fibula. He had been a hard drinker for some years and was drunk at the time of the accident. There was no evidence of definite cardiac disease on examination of the heart and no anasarca was present. No specimen of the urine was obtained. The dislocation was reduced under chloroform soon after admission. On the morning of the $26 \hat{t}$ th the patient showed signs of threatening delirium tremens. He was placed on a bromide mixture and, of course, was on milk diet. He complained of pain in the left side of the chest but no sign of injury or disease was found on examination. Orders were given, however, to paint the painful area with liniment of iodine. When about to do this (at 7.30 P.M.) the nurse placed a bottle containing liniment of iodine on the patient's locker and then left the patient for certainly not more than a minute. During this short period, however, the patient seized the bottle of iodine, uncorked it, and gulped down the whole of the contents, about four ounces. I was in the ward at the time and hearing the other patients call out I turned round in time to see the patient replace the empty bottle on the locker. I at once took steps to wash out the stomach, but in order to do this we were forced to anæesthetise lightly the patient with chloroform. The stomach was then thoroughly washed out until the returning boric lotion was quite clear. On completion of this operation the patient promptly regained con sciousness, his pulse was good, and his condition seemed satisfactory. There was no dyspncea nor was there vomiting or purging. In about an hour's time the pulse became very feeble, the extremities were cold and blue, and the face was cyanosed: respiration was easy kut the patient kept expectorating and complained of some pain in the epigastric region. Five minims of solution of strychnine were injected hypodermically and repeated in two hours as there was no improvement. Hot water bottles were applied and one ounce of brandy was given per rectum. Two drachms of bicarbonate of sodium were given by the mouth in a little water and diluent drinks were ordered. In spite of treatment, however, the patient died from cardiac failure at 11.45 P.M. The coroner, unfortunately, did not order a post-mortem examination to be made.

The case is of interest on account of the rarity of acute iodine poisoning and on account of the rapidity with which death followed the swallowing of the poison in spite of nergetic treatment. Probably this was partly due to the atient having been in a low condition of health on account f his drunken habits.

Dudley.

\section{de}

\section{HOSPITAL PRACTICE, BRITISH AND FOREIGN.}

Nulla autem est alia pro certo noscendi via, nisi quamplurimas et morborum et dissectionum historias, tum aliorum tum propria collectas habere, et inter se comparare.-MoBGAGNI De Sed. et Caus. Morb., lib. iv., Procmium.

\section{POPLAR HOSPITAL.}

A CASE OF SEROUS PLEURAL EFFUSION FOLLOWING ACUTE RHEUMATIC ARTHRITIS AND PERICARDITIS.

(Under the care of Dr. CECIL W ALL.)

For the notes of the case we are indebted to Mr. A. C. Dixon, house physician.

A man, aged 44 years, was admitted into the Poplar Hospital under the care of Dr. Cecil Wall on August 19th, 1904. The patient had been ill for 14 days with acute rheumatic arthritis. There was nothing of importance in his previous history or in his family history; he had not previously suffered from rheumatism. On admission his temperature was $102 \cdot 4^{\circ} \mathrm{F}$.; many joints were hot, red, tender, and swollen, and there was much sweating. The heart was not enlarged but a systolic murmur was heard at the apex and in the axilla accompanying a weak first sound. He was put on full doses of salicylate of sodium and the temperature fell rapidly and reached normal on August $22 n d$. On the 23 rd the temperature rose to $100^{\circ}$ and loud to-and-fro pericardial friction was heard; during the next few days the temperature continued to rise and reached the maximum of $104^{\circ}$ on the 29th. Between these two dates a large pericardial effusion developed and the patient became delirious. After the 29th the temperature began to fall and the pericardial effusion to lessen. On Sept. 6th the area of cardiac dulness was only slightly larger ti an normal but for some days the temperature remained between $100^{\circ}$ and $101^{\circ}$. On Sept. 7 th and 10th the patient had syncopal attacks from which he recovered under the influence of stimulants. Between the 6th and the 15th the pyrexia continued, there was a good deal of diarrhœa, and the patient sank into a typhoid state. Tested on Sept. 14th the blood did not give Widal's reaction. On the 13th signs of pleurisy at the right base developed and an effusion formed of which 29 ounces were evacuated on the 16th. A report upon this fluid is appended. The temperature now gradually fell to normal and on the 20th there was no evidence of pleurisy or of effusion on the right side. Pleural friction, however, was heard in the left axilla. At the beginning of October a fresh effusion formed in the right pleural cavity and 11 ounces were removed by aspiration on Oct. 4th. The signs, however, at the right base persisted and the temperature again rose. An exploring syringe was again inserted on the 21st but only three ounces of fluid were obtained. After this the signs cleared up, the temperature became normal, and the patient made rapid progress towards recovery. He was discharged to a convalescent home on Nov. 22nd. On discharge and when seen about a month later the heart seemed a little enlarged but no murmurs could be heard. In all other respects he seemed perfectly well.

Report on the pleuritic fuid by Miss H. L. BILLETT of the Laboratory of Pathology and Public Health.--" Microscopical examination of the centrifugalised deposit from the fluid showed it to consist chiefly of red blood discs, with a fair number of leucocytes and a small number of endothelial cells. The blood discs are of good colour and the leucocytes appear to be chiefly of the polymorphonuclear type. The coagulum shows a similar composition with the addition of fibrin. No tubercle bacilli have been found in a stained specimen. Plate cultivations were made from the centrifugalised deposit, and an organism was isolated which is similar in microscopical appearance to the rheumatic diplococcus, appearing in pairs, groups, and 
short chains. This was inoculated into various media; a characteristic fine growth was seen on the solid media, and the production of acid was noted in most of the liquid media, witl a sedimentary growth. It does not liquefy gelatine; this organism is thus seen to correspond in many respects with the characters of the diplococcus of acute rheumatism."

Report on the flwid obtained on Oct. 4th by Dr. C. E. HAM, chemival pathologist to the London Hospital.- "The following is a report on pleural fluid sent to me on Oct. 5th. Colour: very pale straw; specific gravity 1018 ; reaction to litmus very faintly alkaline. Chemical examination proteid (albumin and globulin) abont 1.5 per cent. and a substance which reduced Fehling's solution slightly. No formic acid and no lactic acid could be detected. Microscopically practically nothing was seen under oil immersion except a few leucocytes."

Remarks by Dr. WALL, - It is generally accepted that rheumatism may cause pleurisy but it is less commonly held that it may lead to the formation of a clear pleural effusion. In this case bacteriological evidence supports the clinical diagnosis. Dr. G. A. Gibson, in a lecture published this year, says that he is not aware of any case of pleural effusion from which the microcroccus of rheumatism has been isolated. I have not myself been able to find a report of any such case and consequently think that this instance is worthy of record.

\section{DAVID LEWIS NORTHERN HOSPITAL, LIVERPOOL.}

A CASEE OF RUPTURED KIDNEY AND LIVER; OPERATION; (Under the care of Mr. K. W. MonsarRat.)

A MAN, aged 28 years, was admitted on Nov. 26th at 3 P.M. to the Northern Hospital immediately after an accident in which he had been crushed between a wagon and a wall. The patient was very pallid, breathing heavily. His pulse was slow (66 per minute) and he was complaining of great pain in the abdomen. There were no external marks of injury. Palpation of the abdomen revealed nothing, being extremely painful and resistant, but on percussion marked dulness in the left flank was elicited and palpation there caused considerable pain. A catheter was passed and the urine was found to contain blood. Rupture of the left kidney was diagnosed. The pulse-rate increased steadily after admission. At 4.15 P.M. two pints of normal saline solution were injected intravenously previously to operation.

Under ether an oblique incision was made in the left flank, just below the ribs; blood was present in the perinephric tissue. An irregular laceration two inches in length was found on the anterior surface of the kidney at its superior pole; this was stitched up by means of three silk sutures. The peritoneum was incised to the outer side of the descending colon, whereupon a quantity of blood and clots escaped. The hand was then introduced into the peritoneal cavity and the spleen was explored and found to be normal. The hand was then passed across the abdominal cavity and a laceration of the liver was discovered. The lumbar wound was closed, a glass drainage-tube being passed down to the kidney. An anterior incision below the ribs on the right side exposed the liver. The laceration was found on its anterior surface, four or five inches in length, ending on the anterior border about one inch to the outer side of the gall-bladder. Another small tear was present on the anterior border external to the former. The blood and clots were removed as far as possible from the peritoneal cavity and the laceration was packed with gauze; it was not sutured. The parietal incision was closed by through-andthrough sutures of silk-worm gut and the gauze packing was brought through its upper extremity. Two pints of normal saline solution were injected intravenously and a quarter of a grain of morphine and $\frac{1}{1 \frac{1}{5} 0}$ th of a grain of atropine sulphate were administered hypodermically before the patient left the table.

On the next day the patient had not quite recovered from the shock and the collapse. The wounds were dressed and the glass tube to the kidney was replaced by rubber drainage tubing. The gauze drain was removed from the liver as hæmorrhage appeared to have ceased. Atropine sulphate ( $\frac{1}{50}$ th of a grain) was given hypodermically every three hours.

1 Brit. Med. Jour., Jan. 7th, 1905.
On Nov. 28th one grain of cocaine was given every hour because of severe vomiting. Five grains of calomel having been given without result an enema of gruel and turpentine was ordered. The atropine was discontinued and strychmine (four minims every four hours) was substituted. The pulse was feeble, the face was flushed, and the pupils were dilated. The patient complained of a great deal of pain over the wounds. On Nov. 29th another gruel and turpentine enema was given with an excellent result, the general condition being decidedly better in consequence. Blood was now absent from the urine. On Dec. 2nd the condition had greatly improved, except for a superficial skin infection of both wounds, for wlich boric foments were applied every four hours. By Dec. 16th the patient was well on the way to recovery, complete restoration to health being delayed by the complication already referred to.

Remartis by Mr. MossarRat.-The chief complaint made by the patient on admission was agonising pain across the back at the level of the upper lumbar spines. During ex. ploration of the kidney blood was seen to be present in the peritoneal cavity and the peritoneum was incised. Through this incision the spleen, the liver, and the other abdominal organs were examined with the hand and the long tear in the liver was felt with the fingers. Hæmorrhage from the tear in the liver was readily checked by gauze packing ; in addition to the large wound there were several smaller wounds, only one of which, however, involved the peritoneal covering.

Regarding the indications for operation in such a case, in my opinion where definite signs of rupture of the kidney are present operation is always advisable. Agonising lumbar pain is usually present in a characteristic manner in contusion and rupture of the liver and in this case the sions of hæmorrhage into the peritoneal cavity were sufficiently distinct.

\section{Atteroical Socreties.}

\section{PATHOLOGICAL SOCIETY OF LONDON.}

Some Experiments in Connexion with Stimulins.-Demonstration of Cultural Forms of the Leishman Body.

A LABORATORY meeting of this society was held at the Royal Army Medical College, Tictoria Embankment, on March 21st, Sir Jorn BuRdor SANDERson, the President, being in the chair

Major W. B. LeIshmax, R.A.M.C., described a series of experiments demonstrating the Property possessed by Typhoid and Malta Fever Sera of stimulating the Phagocytic Power of Leucocytes derived from Normal Blood towards the Bacillus Typhosus and Micrococcus Melitensis respectively. The first series of experiments were conducted in vitro by Major Leishman's original method of quantitatively estimating the phagocytic power and demonstrated that the addition to normal blood of a very small amount of immune serum, whether derived from a convalescent patient or from an immunised animal, increased the phagocytic power of the normal leucocytes to a very marked degree. The addition of a similar amount of normal serum or of serum derived from men or animals immunised with other germs had either a negative or an inhibitory effect upon phagocytosis. This stimulating effect was found to be exercised only in the case of the particular germ which had been employed in immunisation. It was further shown that the stimulating properties of these sera were not destroyed or diminished by heating to $60^{\circ} \mathrm{C}$. for 15 minutes. In another series of experiments the modification of Major Leishman's method employed by Wright and Douglas in their work on opsonins was adopted. In these the normal corpuscles were freed from the citrated plasma by centrifugalisation and repeated washing in normal salt solution and all the sera subsequently added to these washed corpuscles had been previously heated to $60^{\circ} \mathrm{C}$. for 15 minutes. In this way the thermo-labile opsonins if present in these sera, had been destroyed and the possibility of the stimulin effect being, in part or altogether, due to opsonic action was excluded. In this series immune sera derived from a case of enteric fever and from a rabbit immunised with bacillus typhosus were found to exhibit stimulating properties similar to those of the sera 